their own current knowledge of reality is going to be extremely salient and a very likely answer to a belief question. On this view, the two accounts outlined above are not alternative explanations - both are needed to explain the unusual pattern of responding seen in young children.

In summary, whatever the reason for children's difficulty with belief questions, to couch the problem in terms of a difficulty with currently false beliefs fails to explain an important but often overlooked finding in the literature - namely, children's good performance on memory questions about past reality.

\section{References}

1 Russell, J. (2005) Justifying all the fuss about false belief. Trends Cogn. Sci. 9, 307-308

2 Riggs, K.J. and Simpson, A. (2005) Young children have difficulty ascribing true beliefs. Dev. Sci. 8, 27-30

3 Russell, J. (1996) Agency: Its Role in Mental Development, Erlbaum

4 Perner, J. (1991) Understanding the Representational Mind, MIT Press

5 Peterson, D.M. and Riggs, K.J. (1999) Adaptive modelling and false belief tasks. Mind Lang. 14, 80-112

6 Simpson, A. and Riggs, K.J. (2005) Factors responsible for performance on the day-night task: response set or semantics? Dev. Sci. 8, 360-371

1364-6613/\$ - see front matter $\odot 2005$ Elsevier Ltd. All rights reserved. doi:10.1016/j.tics.2005.07.008

\title{
Comparing cognition across species
}

\section{Simon M. Reader ${ }^{1}$, Daniel Sol ${ }^{2}$ and Louis Lefebvre ${ }^{3}$}

\author{
${ }^{1}$ Behavioural Biology and Helmholtz Institute, Utrecht University, Padualaan 14, PO Box 80086, 3508 TB Utrecht, The Netherlands \\ ${ }^{2}$ Centre de Recerca Ecològica i Aplicacions Forestals (CREAF), Campus de la Universitat Autònoma de Barcelona, E-08193 Bellaterra, \\ Catalonia, Spain \\ ${ }^{3}$ Department of Biology, McGill University, 1205 Dr Penfield Ave., Montréal, Québec, H3A 1B1, Canada
}

We agree with Roth and Dicke [1] that a focus on behavioral flexibility can provide useful operational measures of intelligence [2]. However, we would like to raise a number of issues for discussion. Firstly, the authors do not specify how they have assessed taxonomic differences in behavioral flexibility. Secondly, we believe that using humans as the benchmark against which all other animals are assessed can obscure the elucidation of general evolutionary patterns. We would not argue with the idea that humans excel in a number of cognitive domains, but to search for one defining characteristic of the human brain and to argue that this underpins animal intelligence risks generalizing from a single case. Comparisons of just two or three groups run a similar risk. Instead, comparative analysis is better served by objective, quantitative measures of intelligence on many species and taxa, allowing general patterns to be established.

Thirdly, we are puzzled by Roth and Dicke's partial review of the different ways in which relative brain size has been estimated. Roth and Dicke correctly point out that considering brain mass as a percentage of body mass is often unsatisfactory because such ratios can be confounded with body mass depending on the taxonomic level where they are used. However, other measures of relative brain size (and relative size of certain brain areas) are available and have, in birds and primates, shown very convincing relationships with quantitative measures of cognition such as rate of innovation, rate of tool use, reversal-learning performance, social-learning rate and deception frequency, as well as a number of social and ecological variables [2-4]. These relative brain measures include residual size of the whole brain regressed against body mass, residual size of the mesopallium regressed against body mass, and the volume of the neocortex divided by that of the brainstem. Roth and Dicke may well be correct in espousing the number of neurons or the number of synapses as the ideal neural variable, but until we have such data on many species, we cannot test predictions.

Finally, it must be noted that understanding the evolution of enlarged brains cannot be simply reduced to the demonstration of an association between brain structure and behavioral flexibility. Progress also requires that we understand how enlarged brains and enhanced intelligence help animals to survive and reproduce, and hence increase Darwinian fitness, as well as identifying the costs and constraints that might limit their evolution [5].

\section{References}

1 Roth, G. and Dicke, U. (2005) Evolution of the brain and intelligence. Trends Cogn. Sci. 9, 250-257

2 Lefebvre, L., Reader, S.M. and Sol, D. (2004) Brains, innovations and evolution in birds and primates. Brain, Behav. Evol. 63, 233-246

3 Byrne, R.W. and Corp, N. (2004) Neocortex size predicts deception rate in primates. Proc. R. Soc. Lond. Ser. B 271, 1693-1699

4 Deaner, R.O., Nunn, C.L. and van Schaik, C.P. (2000) Comparative tests of primate cognition: different scaling methods produce different results. Brain Behav. Evol. 55, 44-52

5 Sol, D. et al. (2005) Big brains, enhanced cognition and response of birds to novel environments. Proc. Natl. Acad. Sci. U. S. A. 102, $5460-5465$

1364-6613/\$ - see front matter (C) 2005 Elsevier Ltd. All rights reserved. doi:10.1016/j.tics.2005.07.007 